\title{
On Creep Fatigue interaction of components at elevated temperature
}

\author{
Daniele Barbera \\ Department of Mechanical \& Aerospace Engineering \\ University of Strathclyde, Glasgow, G1 1XJ, UK \\ Haofeng Chen ${ }^{1}$ \\ Department of Mechanical \& Aerospace Engineering \\ University of Strathclyde, Glasgow, G1 1XJ, UK \\ haofeng.chen@strath.ac.uk \\ ASME Membership (8374548)

\section{Yinghua Liu} \\ Department of Engineering Mechanics, \\ Tsinghua University, Beijing, 100084, China
}

\section{ABSTRACT}

The accurate assessment of creep-fatigue interaction is an important issue for industrial components operating with large cyclic thermal and mechanical loads. An extensive review of different aspects of creep fatigue interaction is proposed in this paper. The introduction of a high temperature creep dwell within the loading cycle has relevant impact on the structural behaviour. Different mechanisms can occur, including the cyclically enhanced creep, the creep enhanced plasticity and creep ratchetting due to the creep fatigue interaction. A series of crucial parameters for crack initiation assessment can be identified, such as the start of dwell stress, the creep strain and the total strain range. A comparison between the ASME NH and $R 5$ is proposed, and the principal differences in calculating the aforementioned parameters are outlined. The Linear Matching Method framework is also presented and reviewed, as a direct method capable of calculating these parameters and assessing also the steady state cycle response due to creep and cyclic plasticity interaction. Two numerical examples are presented, the first one is a cruciform weldment subjected to cyclic bending moment and uniform high temperature with different $d$ well times. The second numerical example considers creep fatigue response on a long fibre reinforced Metal Matrix Composite (MMC), which is subjected to a cycling uniform thermal field and a constant transverse mechanical load. All the results demonstrate that the Linear Matching Method is capable of providing accurate solutions, and also relaxing the conservatisms of the design codes. Furthermore, as a direct method it is more efficient than standard inelastic incremental finite element analysis.

Keywords: High Temperature, Cycling load, Creep, Low Cycle Fatigue, Linear Matching Method

\footnotetext{
${ }^{1}$ Corresponding author. Tel.: +44 1415482036
} 


\section{Introduction}

High temperature design and assessment is a challenging field for structural integrity and material science. The ability to design safe and durable structures is an important topic of research for industries and research groups around the world. The power generation industry is one of the most affected by this topic, due to the necessity of ensuring safe and efficient plant operation with a reasonable economic return. Power stations, conventional or nuclear, have many components which are subjected to intense high temperature environments. For fossil fuel fired power plants, the necessity to increase the efficiency of the production cycle by high temperature design is becoming an important milestone in order to make the Carbon Capture System more feasible [1]. Furthermore, Advanced Ultra Super Critical (AUSC) coal fired power plants need to operate at $700{ }^{\circ} \mathrm{C}$ and $300 \mathrm{bar}$, or even higher for the reheat. This aim is very challenging for many aspects of the materials selection and design stages [2]. Problems due to reactor life extension are also present in many nuclear power plants, like the UK Advanced Gas Reactor (AGR), where crack initiation appears in the graphite core and various in other components [3].

Since the beginning of structural integrity research, significant efforts have been made to develop international design and assessment codes for the high temperature response of structures such as the ASME Boiler and Pressure Vessel Code (NH) and the UK R5 high temperature assessment procedure. Each code addresses the possible source of failure in a different way, depending on its temperature and mechanical loading history. These life assessment methods are fundamentally based on experimental and theoretical evidence, which can be used to prepare the failure laws and rules necessary for any component procurement, provided by structural mechanics. The calculation to determine stress intensity level or reference stresses necessary for the design limits are typically carried out using an elastic analysis, and when necessary more complex nonlinear analyses. The elastic analysis based assessment is inevitably over-conservative. To accurately model the material behaviour refined constitutive equations are sometimes used. This approach needs complicated nonlinear finite element analyses, which may be highly complex or computationally expensive.

In the last few decades, in order to avoid complex nonlinear finite element analysis, the Linear Matching Method (LMM) has been developed by Ponter and Chen [4, 5]. LMM has proven its capability of calculating, upper and lower bound shakedown and ratchet limit [6-9], creep rupture limit [10, 11], and creep fatigue assessment [12-15] in a very accurate, robust and efficient way. The LMM is a direct method which is capable of modelling the nonlinear material behaviour of a structure subjected to a cyclic loading condition, through an iterative numerical procedure. This process involves subsequent scaling of the Young's modulus to account for any inelastic strain accumulated at each time point and location of the structure. The nonlinear stress will matches the yield stress at the plastic zone or the creep flow stress if creep is present. To better evaluate nonlinear strains during the saturated load cycle, the RambergOsgood model is implemented for the calculation of plastic strains and a time hardening power-law model is adopted for creep strains during the dwell period [15].

The main objective of this work is to review the creep fatigue interaction, and the structural response of components subjected to cyclic loading conditions. The entire work is divided into three main sections. Section 2 describes the material response to cyclic loads at high temperature environment, identifying the different mechanisms that can occur. In section 3 the key parameters for creep-fatigue evaluation are presented. Both the ASME NH and R5 procedures for creep-fatigue interaction assessment are described and the main differences pointed out. Also in this section the Linear Matching Method capabilities for high temperature assessment are outlined. In section 4, two numerical examples representing real application problems are presented, to show the method capabilities over the design codes and inelastic incremental analyses. 


\section{Material Response to Cyclic Loads at High Temperature Environment}

\subsection{Creep Fatigue Interaction}

Creep and fatigue are complex mechanisms that involve different types of damaging processes. Creep produces intergranular cavitation damage, while fatigue propagates cracks through transgranular paths, with surface striations and wide surface cracks. Relevant works on mapping this interaction was done by Hales [16] and recently reviewed by Yan [17] for 316 stainless steel. Hales used the direct metallographic observation to explain the cyclic creep experimental results. A direct correlation is established between the hold time and the magnitude of the cavitation processes, which increases its magnitude for longer dwell time. Furthermore the creep damage process is strongly affected by the position of the hold time within the loading cycle. The most critical condition occurs when the creep dwell starts at the peak of the tensile stress, introducing signs of intergranular damage even for short periods. In components operating at high temperature creep and fatigue are competing mechanisms, depending on strain range [18] and dwell time. Hales [16] identified four cases of interaction, further extended by Plumbridge [19]. The first case involves "Pure Fatigue" behaviour where surface cracking is dominant. The second case is "Transgranular Competing", which has a transgranular crack propagating during the tensile hold time, and cavitation damage begins to occur. The third case is "Mixed Interaction", where the transgranular cracking switches to the intergranular. The last case is a "Pure Creep" process, where the hold time is long enough to allow the loading cycle to be considered as a monotonic load case. Other parameters like the total strain range were found to be important in this competitive mechanism. For large strain ranges fatigue is dominant, while creep is more damaging for small strain ranges.

Fig. 1 shows a schematic representation of the possible mechanisms, which can occur considering a creep dwell that starts at the peak of the tensile stress. When the load level is below the elastic limit no plastic behaviour takes place at the first cycle (Fig. 1a). The subsequent creep dwell causes a progressive stress relaxation, without any plastic strain during the unloading and loading phases. When the load level is greater than the elastic limit but largely below the shakedown limit, plastic behaviour occurs at the first cycle (Fig. 1b). If the progressive stress relaxation during the subsequent creep dwell is not significant, again there is no plastic strain during the subsequent cycles. The resulting steady state cyclic response is similar to shakedown, and the accumulated creep damage is identical to the monotonic load case. Fig. 1c shows the response of the structure when creep enhanced plasticity occurs during unloading due to the higher load level. In this case a steady state closed loop response appears, and the creep strain range is compensated by the reverse plasticity. If the applied load level continues to increase, the hysteresis loop response shows plasticity during both the loading and unloading phase, causing a more severe fatigue damage which interacts with the creep damage (Fig. 1d). In both Fig. 1c and Fig. 1d, the accumulated creep damage is larger than the one obtained by a monotonic load, due to the higher stress level which cyclically occurs during the creep dwell. For this reason this response is known as "Cyclically Enhanced Creep". In some particular conditions an open hysteresis loop response is possible. This mechanism is known as "Creep Ratchetting" and it will be discussed in the next subsection.

\subsection{Creep Ratchetting Mechanism at High Temperature}

Ratchetting is a cyclic phenomenon, which results in the progressive accumulation of plastic strain. This process can be driven by high mechanical or thermal load level. Thermal ratchetting can occur with very low primary load due to the flow of high temperature fluids, which causes a severe cycling thermal gradient. This behaviour leads to an accumulation of plastic strain [20,21]. From Bree [22] it is known that 
if the structure operates in a region of strict or global shakedown, no inelastic strain accumulation occurs. This statement as discussed in the sub-section 2.1, becomes imprecise if creep occurs [23]. Although creep dwell can introduce a closed hysteresis loop response (Fig. 1c-d) for cyclic loading conditions within the shakedown limit. The closure of the hysteresis loop is due to the compensation of all the inelastic strains within the entire cycle. Anyway the non-closed hysteresis loop would still be possible, when an inelastic strain accumulation occurs due to the dominant creep or reversed plastic strains [15]. For example, a large dwell time could produce creep strain larger than the limited plastic strain, leading to an inelastic strain accumulation creep dominated. In other loading conditions a large stress relaxation, which results in a low level of overall creep stress, leads to an insignificant creep strain but large plastic strain during unloading phase. This could produce an open hysteresis loop dominated by the reversed plastic strain. Hence Creep ratchetting is instead a much more complex mechanism, and it is function of the dwell time, the type of load applied and load levels. In order to better understand the creep ratchetting mechanism, a diagram showing creep ratchetting interaction boundary is given in Fig. 2 . The straight 45 degree line shown indicates the closed hysteresis loop limit. If the loading conditions are within the shakedown limit and no primary load is applied, for any dwell time an identical magnitude of creep strain and net plastic strain is obtained and the closed loop response is possible. In this case the plastic strain at loading and the creep strain are totally recovered by the reversed plasticity. Instead if a primary load is applied depending on its level different behaviours are possible. If the ratio between creep and net plastic strain is above the closed loop limit a creep ratchetting mechanism dominated by creep strain occurs (Fig. $2 a)$, and the entire cycle shifts rightward. Otherwise when the ratio is below the closed loop line a creep ratchetting mechanism dominated by plastic strain occurs (Fig. 2b), and the steady state cycle moves leftward due to the large reverse plasticity. In both cases the creep ratchetting mechanism is driven by the creep dwell period, and the creep ratchet life of the component must be assessed as well as the creep fatigue life.

In all design and assessment codes ratchetting must be avoided [24, 25], and the creep ratchetting Failure (CRF) could be dealt in the same way. It is suggested by [26], that Ratchetting Failure (RF) and Low Cycle Fatigue (LCF) are distinct competitive mechanisms, which can be assessed separately. If the hysteresis loop is closed, then there is no inelastic strain accumulation and the fatigue failure mechanisms can be predicted using the Manson-Coffin relationship [26]. However if the failure occurs due to necking (RF or CRF) the ductility exhaustion approach is used:

$$
N_{r}=\frac{\varepsilon_{f}}{\Delta \varepsilon_{r}}
$$

where $\varepsilon_{f}$ is the tensile ductility of the material, and $\Delta \varepsilon_{r}$ is the accumulation of inelastic strain per cycle. Recent development in non-linear material modelling allows for more detailed consideration [27]. It is shown that the ratchetting mechanism can affect the LCF life, only when the loading level is near the static limit load of the structure. The intensified plastic strain accumulation due to ratchetting affects the crack initiation and propagation, especially where stress concentration are present. It is reasonable to assume that creep-ratchetting can be assessed independently from creep fatigue process in the most cases.

\subsection{Creep and Fatigue Total Damage Calculation}


In order to estimate the total damage caused by creep and fatigue interaction, a damage diagram must be defined. Different relationships between fatigue and creep can be established, and the most commonly used is the bi-linear relationship adopted by ASME NH [24];

$$
\phi_{f}+\phi_{c} \leq D
$$

where $\phi_{f}$ and $\phi_{c}$ are the accumulated fatigue and creep damage, and D is an allowable creep-fatigue damage factor which depends on the material. If the total damage $D$ is equal to the unity the linear diagram is obtained, as shown in Fig. 3, where the creep-fatigue damage diagrams and experimental data for type 304SS at different total strain ranges are presented as an example. The bi-linear locus shows a focal point where the creep and fatigue damage is equal to 0.3 , which is a material constant. Another way to model this interaction is given by Skelton [28], who introduced a coupled model for creep-fatigue damage interaction shown in Fig. 3. It is based on the assumption that a creep fatigue interaction exists and the total damage is not equal to the unity. When the total damage to failure is lower than the unity, the failure locus has a concave shape with an upward facing curve. The failure locus is described by the following relationship:

$$
\frac{\phi_{f}}{1-\phi_{c}}+\frac{\phi_{c}}{1-\phi_{f}}=1
$$

The focal point on the diagram is 0.33 , close to the one predicted by the bi-linear method. This relationship can be easily modified if a damage de-coupling is necessary, introducing two interaction coefficients $I_{f c}$ and $I_{c f}$ attenuating effect of fatigue on creep and vice versa. Equation (3) is then modified in the following way:

$$
\frac{\phi_{f}}{1-I_{c f} \phi_{c}}+\frac{\phi_{c}}{1-I_{f c} \phi_{f}}=1
$$

By the adoption of such a formulation and properly calculating the interaction coefficients, it is possible to model the different interaction mechanisms.

\section{Evaluation of Key Parameters for the Creep-Fatigue Assessment}

\subsection{Key Parameters for Creep fatigue Assessment}

When creep and fatigue affect a structure, a series of parameters need to be calculated to perform the crack initiation assessment. These parameters are defined in Fig. 4, where a typical steady state cycle with a tensile peak creep dwell is shown. The three most important parameters are highlighted in yellow, which are the stress at the start of the dwell $\sigma_{1}$, the elastic follow up factor $Z$ and the total strain range $\Delta \varepsilon_{t o t}$. Other parameters can be used to accurately define the hysteresis loop such as the creep stress drop $\Delta \sigma_{c r}$, the associated creep strain $\Delta \varepsilon_{c r}$ and the plastic strain $\Delta \varepsilon_{p}$ accumulated within the cycle. 
The only way to obtain these parameters and assess the steady state cycle is by adopting inelastic step-by-step finite element analyses, or by using a more convenient direct methods such as the Linear Matching Method. Inelastic incremental finite element analyses are able to identify the structural response due to creep and fatigue interaction. However, these are computationally inefficient especially when 3D elements are used, and convergence issues can occur. Conversely, direct methods such as the LMM have been demonstrated to be capable of providing alternative solutions to engineering problems, providing all the necessary parameters to perform a crack initiation analysis, and can be easily adapted to any design code. The design codes such as R5 or ASME, are widely adopted and capable of calculating the key aforementioned parameters by adopting a series of design rules and procedures. In the majority of the cases, these procedures rely on linear elastic analysis. However, in certain cases when conservatisms need to be relaxed, then an inelastic material response can be implemented. Despite this there is no real interaction between creep and fatigue, which are evaluated separately. Their interaction relies mostly on safety factors, which enhance the calculated parameter. These design rules provide a conservative but safe assessment for a large class of components used by industry.

\subsection{ASME NH and R5 Creep-Fatigue Damage Assessment Procedures}

The most crucial aspect of any creep fatigue assessment procedure is to identify the structural response due to a cyclic load. This means constructing an accurate hysteresis loop, in order to evaluate the creep and fatigue damage. All assessment codes consider an open loop response unacceptable (Fig. $2 \mathrm{a}$ and Fig. $2 \mathrm{~b}$ ). For this reason only the closed loop response will be considered (Fig. 1c-d), and creep ratchetting is neglected.

Both ASME NH and R5 procedures rely on simplified methods to address the stress calculation, and make extensive use of stress categorization. Different types of analyses can be used, from pessimistic elastic analyses to more complex and less conservative inelastic analyses. As shown in Fig. 4 a series of parameters are crucial for the accurate assessment of crack initiation with creep-fatigue interaction. The first parameter is the stress at the start of the creep dwell $\sigma_{1}$, which is estimated by both codes in different ways. ASME NH calculates this stress by adopting a revised effective creep stress, which is equal to 1.25 times the effective creep stress. The effective creep stress is obtained by multiplying the yield stress of the material at creep temperature for a stress factor $Z^{\mathrm{NH}}$, which is not the elastic follow up factor. The value of $Z^{\mathrm{NH}}$ depends on the level of primary and secondary stress for the cyclic loading condition considered, which is properly described by NH-T-1332 [24]. R5 instead has two options to calculate the start of the dwell stress; the first adopts the shakedown reference stress. Otherwise a second option can be considered, if the peak stress is not included in the shakedown reference stress. A revised steady state equivalent stress at the start of the creep dwell is obtained by subtracting the shakedown stress limit from the maximum equivalent elastic stress range.

Once the start of the dwell stress is calculated the second parameter, the creep strain, is assessed by both the codes with different procedures. ASME NH calculates the creep strain by using the isochronous stress-strain curve at the revised effective creep stress for the holding temperature and time [24]. Whereas, in $\mathrm{R} 5$, the creep strain range $\Delta \bar{\varepsilon}_{c}$ is obtained using the following relationship:

$$
\Delta \bar{\varepsilon}_{c}=-\frac{Z}{\bar{E}} \Delta \bar{\sigma}
$$


where $\bar{E}$ is the effective Young's modulus, $Z$ is the elastic follow-up factor and $\Delta \bar{\sigma}$ is the equivalent stress drop during the dwell period. The inaccurate calculation of the stress drop and $Z$ factor may introduce an overly conservative creep strain. The concept of the elastic follow up factor was introduced in $\mathrm{R} 5$ to avoid fully inelastic time dependent analyses. There are three options available to calculate it, and the most accurate is the one which uses an elastic-creep inelastic analysis. In such a type of analysis no plastic behaviour is considered and a monotonic load is applied rather than a cyclic one. This procedure does not take into account cyclic plasticity, in order to reduce the computational effort.

The last parameter which needs to be calculated in order to start the crack initiation assessment is the total strain range $\Delta \varepsilon_{\text {tot }}$. Both assessment procedures adopt the Neuber correction in order to calculate the plastic strain from the elastic solution, but R5 differs by also using the Ramberg-Osgood material model for the cyclic material response. Furthermore, both procedures consider different modifiers to account for the local geometric concentration factor and multiaxial plasticity. In the ASME NH the total strain range is defined as:

$$
\Delta \varepsilon_{t o t}^{N H}=K_{v} \cdot \Delta \varepsilon_{\bmod }+K \cdot \Delta \varepsilon_{c}
$$

where $K$ is the local concentration factor, $K_{v}$ is the multiaxial plasticity and Poisson ratio adjustment, $\Delta \varepsilon_{\text {mod }}$ is the modified maximum strain range and $\Delta \varepsilon_{c}$ is the creep strain range [24, 29]. The modified maximum strain range can be calculated by three options, with an increasing amount of conservatism. All the three methods use the maximum equivalent elastic strain range as starting point. Different factors are considered to enhance the elastic strain range due to non-linear effects.

The R5 has a similar procedure and calculates the total equivalent strain range as follows:

$$
\Delta \varepsilon_{t o t}^{R 5}=\Delta \varepsilon_{e l, r}+\Delta \varepsilon_{p}+\Delta \varepsilon_{v o l}
$$

where the first term is the revised equivalent elastic strain range, which is obtained by dividing the sum of maximum equivalent elastic stress and stress drop due to creep by the effective Young's modulus. The second term represents an enhancement of the elastic strain range due to plasticity. The last term is a correction to the change of constant volume during plastic deformation and creep (Appendix A7) [25].

Once these parameters are determined the fatigue and creep damage can be calculated and the total damage is determined by using the appropriate interaction rule. Both codes produce similar results in terms of fatigue damage, but differences can occur if the creep strain is dominant [30]. Both codes address the fatigue damage by adopting the Miner's law. R5 accounts for the crack initiation by calculating the number of cycles $N_{i}$ necessary to produce a crack of size $a_{i}$, and the number of cycles $N_{g}$ to make the crack grow to the final size $a_{0}$. This allows separating the crack initiation and growth process therefore the size effect issue can be assessed.

The two design codes address the creep damage in different ways. ASME NH adopts the Time Fraction (TF) rule to calculate the creep damage

$$
d_{c}^{T F}=\int_{0}^{t_{h}} \frac{d t}{t_{f}(\sigma, T)}
$$


where $t_{f}$ is the creep rupture time obtained by creep rupture tests, and it is function of stress and temperature. $d t$ is the time increment and $t_{h}$ is the hold time. Despite its simplicity this approach is not conservative for small strain range without proper safety factors, and becomes over conservative for high stress dwell period [30,31]. In contrast to this, the R5 procedure adopts the Ductility Exhaustion (DE) that is determined by using the following relationship:

$$
d_{c}^{D E}=\int_{0}^{t_{h}} \frac{\dot{\bar{\varepsilon}}_{c}}{\bar{\varepsilon}_{f}\left(\dot{\bar{\varepsilon}}_{c}, T\right)} d t
$$

where $t_{h}$ is the dwell time, $\dot{\bar{\varepsilon}}_{c}$ is the instantaneous creep strain rate and $\bar{\varepsilon}_{f}$ is the material creep ductility. The results generated by the DE produces less scattering results compared to the TF, making DE more accurate [17]. Despite the reasonable conservative predictions given by the $D E$, when the initial stress is low, overly conservative results are obtained. This behaviour was studied by Spindler [31], who developed a "Stress Modified Ductility Exhaustion" approach to overcome this issue. Furthermore this approach gives a better prediction of the creep damage due to intermediate creep dwell during the load cycle, in a typical power plant operating scenario [32, 33].

\subsection{LMM for Creep Fatigue Assessment}

Contrary to the R5 and the ASME NH which are rules based procedures, the Linear Matching Method is a numerical method which is based on solid mechanics concepts. It allows assessing the steady state cycle response (Fig. 4) of a structure subjected to a cycling thermo mechanical load. As a numerical method, it is capable of calculating the steady state cycle response, accounting for the cyclic plasticity and its interaction with a creep dwell. This means that all the key parameters summarized in Fig. 4 are numerically calculated in a much more accurate way, rather than using design rules and assumptions. The solutions obtained by the LMM are always accurate, and allows a valid reduction of conservatism compared to R5 [34].

The Extended LMM Direct Steady Cycle Analysis (DSCA) is capable of evaluating the low cycle fatigue response with creep dwell within the loading cycle [15]. The extended LMM DSCA is able to obtain all the key engineering parameter necessary for the construction of the hysteresis loop. At the end of the entire procedure the following parameters are determined; the elastic and plastic strains during loading and unloading phase, the creep strain and the associated stress drop, the stress level at the end of each load instance, and the elastic follow-up factor due to the dwell period.

The extended DSCA analysis determines the structural response to a cyclic loading case under high temperature condition, evaluating the accumulation of residual stress field due to plastic or creep responses at the steady state cycle. The procedure consists of a number of iterative sub-cycles, defined as $m=1,2 \ldots M$, where each $m^{\text {th }}$ sub-cycle is repeated until convergence is achieved. The each sub-cycle will perform $\mathrm{N}$ increments, where $\mathrm{N}$ is the total number of loading instances. For each $\mathrm{n}^{\text {th }}$ increment an augmented elastic stress field is calculated for load instance $t_{n}$, adding the accumulated residual stress for the $\mathrm{n}^{\text {th }}$ load instance at the $\mathrm{m}^{\text {th }}$ cycle of iteration. If creep is not relevant, the plastic strain amplitude is calculated and can be used to update the yield stress if a Ramberg-Osgood (RO) material model is used. Alternatively if creep occurs the creep strain is calculated using the Norton Bailey creep constitutive model [15]. The creep strain rate and creep flow stress are also obtained. This procedure provides a more accurate prediction of creep stress at the start and end of the dwell time than the R5 or ASME NH. It 
directly incorporates the basic creep material properties, and it is independent of the elastic follow-up factor. At the beginning of the iterative process an initial estimation of the stress at the start and end of the dwell is provided. This prediction is adjusted at each $\mathrm{m}^{\text {th }}$ sub-cycle until the converged solution for the entire hysteresis loop is obtained giving the converged value of creep flow stress. For each load instance a residual stress field is calculated within the $\mathrm{m}^{\text {th }}$ sub-cycle, and the shear modulus is updated for the next sub-cycle using the linear matching equation with either the yield stress or creep flow stress.

Once this procedure is completed, the complete cyclic response of the structure is determined and the creep fatigue damage calculation is performed. Fatigue damage is assessed using material endurance data or Manson-Coffin relationship [35], while the creep damage can be determined by the time fraction approach [29], or by the creep ductility exhaustion method. These procedures are all implemented in the extended LMM DSCA code and can be further developed to match any aspect of the assessment code considered. The most significant benefit of this method is the ability to solve a complex nonlinear problem with creep fatigue interaction, through simple iterative linear elastic calculations, with much lower computational costs than traditional step-by-step analyses.

\section{LMM Cases of Study}

\subsection{Creep Fatigue Assessment on Cruciform Weldment}

In this section an overview of recent works [12-14] on the creep fatigue interaction of weldment is presented. The LMM evaluation of the creep fatigue life of a cruciform weldment subjected to a cyclic bending moment and a uniform high temperature is summarized here. The aim of this research is to study the influence of an applied bending moment on the creep-fatigue interaction. The results obtained by the numerical analysis are compared with experimental laboratory tests. Within this work the welding residual stresses are neglected, because the specimens tested were carefully manufactured and treated in order to minimize the welding residual stresses. Furthermore, their inclusion in the model could make it difficult to analyze the effects of the applied bending moment and the corresponding residual stresses on the creep-fatigue interaction. Fig. 5 shows the Finite Element model, which is composed of 978 8-node biquadratic plane strain quadrilateral elements with a reduced integration scheme. In order to simulate the reverse bending moment $M$, a cycling linear distribution of normal pressure $P$ is applied to the end face of the model. Creep behaviour is introduced through a high temperature hold period $\Delta t$. The material used for the cruciform weld is stainless steel $316 \mathrm{~N}(\mathrm{~L})$ at $550{ }^{\circ} \mathrm{C}$. The mechanical properties vary for the parent, weld or HAZ section. The cyclic stress strain response is modelled using the RambergOsgood formulation:

$$
\begin{aligned}
\frac{\Delta \varepsilon_{t}}{2} & =\frac{\Delta \sigma}{2 \bar{E}}+\left(\frac{\Delta \sigma}{2 B}\right)^{\frac{1}{\beta}} \\
\bar{E} & =\frac{3 E}{[2(1+v)]}
\end{aligned}
$$

where $\Delta \varepsilon_{t}$ is the total strain range, $\Delta \sigma$ the total stress range, $\bar{E}$ is the effective multi axial Young's modulus defined by using the elastic material properties. $B$ and $\beta$ are the cyclic plastic constants and are obtained by fitting the experimental cyclic curves for different strain ranges. The creep strain calculation is based on the Norton-Bailey power law in its "time hardening" form. The extended LMM DSCA procedure 
is used to determine the steady state response and to calculate the total strain range, the creep strain and stress. The fatigue damage is addressed using the calculated total strain range and existing LCF data available in R66 [25], and the creep damage is calculated using the time fraction method.

The study included 5 variants of the bending loads, which correspond to the following total strain ranges at the outer surface of parent material; $0.25 \%, 0.3 \% 0.4 \%, 0.6 \%$ and $1.0 \%$. Three creep-fatigue scenarios are considered; no creep dwell, 1 hour and 5 hours of creep dwell. Detailed contour plots of LMM results for the weldment are presented in Fig. 6, which corresponds to a total strain range of $1 \%$ and 5 hours of dwell period. The most critical location is the weld toe, near the Heat Affected Zone, and an end life of 228 cycles is estimated. A comparison [12] between simulation results and the available experimental data showed an optimal match for 9 of the 11 available. Numerical results appear to produce conservative prediction for a dwell period of 1 hour and optimal for 5 hours. The pure fatigue results are slightly non-conservative, but are still within an acceptable range.

This numerical example shows the LMM capability of providing all the essential engineering parameters necessary to characterise the creep fatigue damage interaction of a weldment, estimating the creep fatigue damage, the lifetime and the location of the failure in an accurate and efficient way. Furthermore, the efficiency of the LMM, makes it possible to study different loading conditions which are not covered by real experimental works. This is important for creep-fatigue assessment, especially when longer high temperature dwell times are considered, making it very expensive to perform a full scale test.

\subsection{Creep Fatigue Interaction of a Metal Matrix Composite}

In this sub-section a micromechanical modelling on creep fatigue interaction of a metal matrix composite is presented. The results obtained are an extension of a previous work [36] that focused on the impact of dwell time on the structural response to the applied cyclic load. The same elastic and creep material properties are adopted. The mesh is composed of 1039 8-node biquadratic plane strain quadrilateral elements, with a reduced integration scheme. A quarter of the elementary unit cell is modelled as shown in Fig. 7, and two planes of symmetry are applied as boundary conditions. Furthermore plain conditions are imposed on the upper and right external face to simulate the periodic boundary condition. The entire model is subjected to a uniaxial constant mechanical load and a cyclic uniform thermal load with a hold time $\Delta t$. In contrast to the previous work [36] which considered an Elastic Perfect Plastic (EPP) material model for the matrix, the Ramberg-Osgood (RO) model is adopted. The creep fatigue interaction is calculated by considering the competitive behaviour law formulated by Skelton [28], but neglecting any de-coupling factors.

A comparison between EPP and RO for a mechanical load of 86.25 MPa and a cycling temperature of $175^{\circ} \mathrm{C}$ is shown in Fig. 8, which reports the number of cycles to failure against dwell time with two distinct areas. The first area is fatigue dominated, and for this particular loading condition within the elastic shakedown limit, it is the High Cycle Fatigue (HCF) when the dwell time is less than 0.01 hours. Instead when the dwell time is greater than 0.1 hours LCF starts to dominate. In this region the EPP is slightly less conservative than the RO due to the applied low load level, which does not exhibit hardening effect. The second area is creep dominated, showing a similar number of cycles to failure from both models. It is worth noting that for large hold times a steady state stress level is reached at the end of the dwell for both material models. For a much hold time, the creep damage accumulated after reaching the steady state creep stress is much larger than the sum of fatigue damage during the cycle and creep damage accumulated before reaching the steady state creep stress. The damage interaction diagram is shown in Fig. 8 for different mechanical load levels and dwell times, at the cycling temperature of $175^{\circ} \mathrm{C}$. Three 
plots of the creep and fatigue damage against the dwell time are also shown in Fig. 8 . When the mechanical load is absent, creep damage is relatively small, as the creep stress produced by the thermal load is fully relaxed when it reaches a steady state. When the mechanical load is increased to $86.25 \mathrm{MPa}$, creep becomes dominant for dwell times longer than 1 hour, and a remarkable increase in the damage is observed at around 100 hours. The number of cycles to failure reduces from 237 for the 1 hour case to 43 for 100 hours. This trend is the same for the last case where a mechanical load of $172.5 \mathrm{MPa}$ is applied. In this case for dwell times longer than 1000 hours the failure is predicted to occur during the first cycle, and the failure is driven by creep rupture damage. The visualization of stress and strain is important in order to understand how the creep and fatigue damages interact with each other. Fig. 10 and Fig. 11 show the stress (normalized by the yield stress) and the strains evolution at loading, creep and unloading phases for different dwell times when the MMC is subjected to a cycling temperature of $175^{\circ} \mathrm{C}$ and a constant mechanical load of $172.5 \mathrm{MPa}$. For this cyclic loading condition fatigue is the driving mechanism for a hold time less than around 0.5 hours. The unloading phase is the most affected by the creep dwell, which introduces an increased stress relaxation around the fibre with the increased dwell time.

Comparisons are made between the LMM, the inelastic step-by-step (SBS) analyses and the design codes. For this purposes, a single cyclic load point with a constant mechanical load of $86.25 \mathrm{MPa}$ and a cycling temperature range of $175^{\circ} \mathrm{C}$ is considered for two dwell times. The parameters obtained are shown in Table 1, but due to the lack of material data the ASME NH is excluded from this comparison. The R5 and the LMM produce similar stresses at the start of creep dwell and creep strain when a 1 hour dwell is considered. Instead the equivalent plastic strain range from the R5 is slightly more conservative. When the creep dwell is increased to 100 hours, differences start to increase. The longer dwell time introduces a larger reverse plasticity during the unloading phase due to the stress relaxation during the dwell, causing a change of the critical location. This change of mechanism is identified by the LMM but not by the R5, which uses the maximum elastic stress as a starting point for all the calculations. Despite this the total strain range predicted by the R5 is still more conservative. Conversely, the SBS always provides similar results to the LMM, confirming its accuracy. In terms of computational time, the LMM is much more efficient than the SBS, which is crucial when assessing highly complex problems.

\section{Conclusions}

An overview of the main aspects of creep fatigue interaction in structures at high temperature is given. Creep dwell within a cyclic load is confirmed to cause a series of dangerous mechanisms, including the creep enhanced plasticity/fatigue, cyclically enhanced creep damage, and creep ratchetting. If the creep fatigue interaction produces a closed hysteresis loop response the damage originates due to the combined action of the cyclically enhanced creep and the increased fatigue damage due to the stress relaxation during the dwell period. Alternatively if the creep strain becomes too large to be compensated by the reverse plastic strain, or the significant stress drop during the dwell period leads to a large reversed plastic strain, the hysteresis closed loop may become open. This inelastic strain accumulation is known as "Creep Ratchetting", and has been recommended to be assessed separately with the creep fatigue damage assessment.

The main differences and crucial points for the creep fatigue interaction assessment of both ASME $\mathrm{NH}$ and R5 have been reviewed. It worth nothing that both codes adopt conservatisms in the entire creep fatigue assessment procedure. In terms of creep damage assessment, the use of creep ductility and stress modified creep ductility allows R5 producing less overly conservative results for any strain ranges. Another point of difference is the material selection, which for the ASME is very strict, where as the R5 is 
flexible and allows the user to make the appropriate selection. This difference becomes crucial when assessing new components, which are intended to operate at extremely high temperatures where creep is dominant. R5 can be used in addition to the ASME NH when this provides overly conservative results due to extreme cyclic loading conditions.

Direct methods such as the LMM represent a robust conjunction between the rules based methods and the incremental inelastic analyses. The LMM provides a perfect balance between the conservatism of the rules based methods and the accuracy of inelastic numerical analyses. An overview of the LMM Extended DSCA capability of assessing practical complicated industrial components has been provided through two numerical examples. A cruciform weldment is investigated for different applied cyclic load levels and dwell times, and all the key parameters including creep and fatigue damages leading to lifetime prediction are successfully calculated. In the second example a detailed creep fatigue interaction study of a fibre reinforced MMC subjected to a cycling thermal load and a constant mechanical one is presented. Creep and fatigue damages appear to be competitive for low level of stress, instead for high stress level or long dwell creep damage becomes dominant. A comparison between LMM, SBS and R5 procedure has been presented for a cyclic loading point for two different dwell times. It is demonstrated that the LMM is more efficient than inelastic analyses, and also capable of relaxing the R5 conservatism, and providing accurate and robust solutions.

\section{Acknowledgement}

The authors gratefully acknowledge the support of the University of Strathclyde, the Royal Academy of Engineering, the Royal Society (IE140842), the International Cooperation and Exchange Project NSFC (11511130057) and the National Science Foundation for Distinguished Young Scholars of China (11325211) during the course of this work.

\section{References}

[1] Weitzel, P., 2011, "Steam Generator for Advanced Ultra-Supercritical Power Plants 700 to 760C."

[2] Starr, F., 2014, "3 - High temperature materials issues in the design and operation of coalfired steam turbines and plant," Structural Alloys for Power Plants, A. Shirzadi, and S. Jackson, eds., Woodhead Publishing, pp. 36-68.

[3] O’Donnell, M., Bradford, R., Dean, D., Hamm, C., and Chevalier, M., 2011, "High Temperature Issues in Advanced Gas Cooled Reactors (AGR)."

[4] Ponter, A. R. S., and Chen, H., 2001, "A minimum theorem for cyclic load in excess of shakedown, with application to the evaluation of a ratchet limit," European Journal of Mechanics - A/Solids, 20(4), pp. 539-553.

[5] Chen, H. F., and Ponter, A. R. S., 2001, "Shakedown and limit analyses for 3-D structures using the linear matching method," International Journal of Pressure Vessels and Piping, 78(6), pp. 443-451.

[6] Chen, H., and Ponter, A. R. S., 2009, "Structural integrity assessment of superheater outlet penetration tubeplate," International Journal of Pressure Vessels and Piping, 86(7), pp. 412-419. [7] Lytwyn, M., Chen, H., Martin, M., Lytwyn, M., Chen, H., and Martin, M., 2015, "Comparison of the linear matching method to Rolls Royce's hierarchical finite element framework for ratchet limit analysis," International Journal of Pressure Vessels and Piping, 125, pp. 13-22. 
[8] Ure, J. M., Chen, H., and Tipping, D., "Development and implementation of the ABAQUS subroutines and plug-in for routine structural integrity assessment using the Linear Matching Method," Proc. SIMULIA Community Conference 2012,(Formerly the ABAQUS Users Conference).

[9] Chen, H., 2010, "Lower and Upper Bound Shakedown Analysis of Structures With Temperature-Dependent Yield Stress," Journal of Pressure Vessel Technology, 132(1), p. 011202. [10] Chen, H. F., Engelhardt, M. J., and Ponter, A. R. S., 2003, "Linear matching method for creep rupture assessment," International Journal of Pressure Vessels and Piping, 80(4), pp. 213-220.

[11] Chen, H. F., Ponter, A. R. S., and Ainsworth, R. A., 2006, "The linear matching method applied to the high temperature life integrity of structures. Part 1. Assessments involving constant residual stress fields," International Journal of Pressure Vessels and Piping, 83(2), pp. 123-135.

[12] Gorash, Y., and Chen, H., 2013, "Creep-fatigue life assessment of cruciform weldments using the linear matching method," International Journal of Pressure Vessels and Piping, 104(0), pp. 113.

[13] Gorash, Y., and Chen, H., 2013, "On creep-fatigue endurance of TIG-dressed weldments using the linear matching method," Engineering Failure Analysis, 34(0), pp. 308-323.

[14] Gorash, Y., and Chen, H., 2013, "A parametric study on creep-fatigue endurance of welded joints," Proceedings in Applied Mathematics and Mechanics, 13(1), pp. 73-74.

[15] Chen, H., Chen, W., and Ure, J., 2014, "A Direct Method on the Evaluation of Cyclic Steady State of Structures With Creep Effect," Journal of Pressure Vessel Technology, 136(6), pp. 061404-061404.

[16] Hales, R., 1980, "A quantitative metallographic assessment of structural degradation of type 316 stainless steel during creep-fatigue," Fatigue \& Fracture of Engineering Materials \& Structures, 3(4), pp. 339-356.

[17] Yan, X.-L., Zhang, X.-C., Tu, S.-T., Mannan, S.-L., Xuan, F.-Z., and Lin, Y.-C., 2015, "Review of creep-fatigue endurance and life prediction of 316 stainless steels," International Journal of Pressure Vessels and Piping, 126-127(0), pp. 17-28.

[18] Miller, D., Priest, R., and Ellison, E., 1984, "A review of material response and life prediction techniques under fatigue-creep loading conditions," High-temperature materials and processes, 6(3-4), pp. 155-194.

[19] Plumbridge, W., 1987, "Metallography of high temperature fatigue," High Temperature Fatigue, Springer, pp. 177-228.

[20] Kobayashi, M., Ohno, N., and Igari, T., 1998, "Ratchetting characteristics of 316FR steel at high temperature, part II: Analysis of thermal ratchetting induced by spatial variation of temperature," International Journal of Plasticity, 14(4-5), pp. 373-390.

[21] Ohno, N., Abdel-Karim, M., Kobayashi, M., and Igari, T., 1998, "Ratchetting characteristics of 316FR steel at high temperature, part I: Strain-controlled ratchetting experiments and simulations," International Journal of Plasticity, 14(4-5), pp. 355-372.

[22] Bree, J., 1967, "Elastic-plastic behaviour of thin tubes subjected to internal pressure and intermittent high-heat fluxes with application to fast-nuclear-reactor fuel elements," The Journal of Strain Analysis for Engineering Design, 2(3), pp. 226-238.

[23] Bree, J., 1968, "Incremental growth due to creep and plastic yielding of thin tubes subjected to internal pressure and cyclic thermal stresses," The Journal of Strain Analysis for Engineering Design, 3(2), pp. 122-127.

[24] American Society of Mechanical Engineers, B., and Pressure Vessel, C., 2007, ASME boiler \& pressure vessel code : an international code, New York, N.Y. : American Society of Mechanical Engineers. 
[25] Ainsworth, R., 2003, "R5: Assessment procedure for the high temperature response of structures," British Energy Generation Ltd, 3.

[26] Kapoor, A., 1994, "A re-evaluation of the life to rupture of ductile metals by cyclic plastic strain," Fatigue \& fracture of engineering materials \& structures, 17(2), pp. 201-219.

[27] Weiß, E., Postberg, B., Nicak, T., and Rudolph, J., 2004, "Simulation of ratcheting and low cycle fatigue," International Journal of Pressure Vessels and Piping, 81(3), pp. 235-242.

[28] Skelton, R. P., and Gandy, D., 2008, "Creep - fatigue damage accumulation and interaction diagram based on metallographic interpretation of mechanisms," Materials at High Temperatures, 25(1), pp. 27-54.

[29] Jetter, R. I., 2002, "Subsection NH-Class 1 Components in Elevated Temperature Service," American Society of Mechanical Engineers, New York, pp. 369-404.

[30] Sheridan, M., Knowles, D., and Montgomery, O., "Comparison of R5 and ASME NH CreepFatigue Damage Assessment Methodologies," Proc. ASME 2013 Pressure Vessels and Piping Conference, American Society of Mechanical Engineers, pp. V01AT01A046-V001AT001A046.

[31] Spindler, M. W., 2007, "An improved method for calculation of creep damage during creepfatigue cycling," Materials Science and Technology, 23(12), pp. 1461-1470.

[32] Spindler, M., 2005, "The prediction of creep damage in type 347 weld metal. Part I: the determination of material properties from creep and tensile tests," International journal of pressure vessels and piping, 82(3), pp. 175-184.

[33] Spindler, M. W., 2005, "The prediction of creep damage in Type 347 weld metal: part II creep fatigue tests," International Journal of Pressure Vessels and Piping, 82(3), pp. 185-194.

[34] Chen, H. F., Ponter, A. R. S., and Ainsworth, R. A., 2006, "The linear matching method applied to the high temperature life integrity of structures. Part 2. Assessments beyond shakedown involving changing residual stress fields," International Journal of Pressure Vessels and Piping, 83(2), pp. 136-147.

[35] Manson, S., and Halford, G. R., 2009, Fatigue and durability of metals at high temperatures, ASM International.

[36] Barbera, D., Chen, H., and Liu, Y., 2015, "On the creep fatigue behaviour of metal matrix composites," International Conference on Pressure Vessel Technology Shangai, China. 


\section{Table Captions}

Tab. 1

Comparison between Linear Matching Method, incremental inelastic analysis and R5 assessment procedure. 
Table 1 Key parameters for crack initiation assessment obtained with different methods, the stress at the start of dwell $\sigma_{1}$ is expressed in MPa and the computational Time in seconds.

\begin{tabular}{ccccccccccccc}
\hline \multicolumn{1}{c}{ Dwell time 1 hr } & \multicolumn{1}{c}{ Dwell time $100 \mathrm{hrs}$} \\
\hline & $\sigma_{1}$ & $\mathcal{E}^{c r}$ & $\Delta \varepsilon_{p}$ & $\Delta \varepsilon_{\text {tot }}$ & Time & $\sigma_{1}$ & $\mathcal{E}^{c r}$ & $\Delta \varepsilon_{p}$ & $\Delta \varepsilon_{\text {tot }}$ & Time \\
LMM & 132 & $7.61 \mathrm{E}-05$ & $8.08 \mathrm{E}-05$ & $5.86 \mathrm{E}-03$ & 360 & 172 & $1.15 \mathrm{E}-03$ & $7.48 \mathrm{E}-04$ & $6.69 \mathrm{E}-03$ & 420 \\
SBS & 131 & $7.60 \mathrm{E}-05$ & $7.60 \mathrm{E}-05$ & $5.75 \mathrm{E}-03$ & 1320 & 173 & $1.20 \mathrm{E}-03$ & $7.76 \mathrm{E}-04$ & $6.65 \mathrm{E}-03$ & 1440 \\
R5 & 130 & $5.69 \mathrm{E}-05$ & $1.22 \mathrm{E}-03$ & $7.72 \mathrm{E}-03$ & NA & 130 & $6.16 \mathrm{E}-04$ & $1.54 \mathrm{E}-03$ & $8.55 \mathrm{E}-03$ & NA
\end{tabular}




\section{Figure Captions}

Fig. 1 Different material response due to cyclic loading with creep dwell period at the tensile peak

Fig. 2 Creep ratchetting interaction boundary and creep ratchetting response due to creep stain (a) and plastic strain (b)

Fig. 3 Type $304 \mathrm{SS}\left(595^{\circ} \mathrm{C}\right)$ damage diagram for bi-linear, linear and combined damage rules $[28,29]$

Fig. $4 \quad$ Saturated Steady State Cycle with creep dwell at tensile peak

Fig. 5 Geometry and Finite Element Model of type 2 cruciform weldment [12]

Fig. 6 Contour plots of LMM results for type 2 weldment corresponding to $\Delta \varepsilon_{\text {tot }}=1 \%$ and $\Delta t=$ 5 hours of dwell period [12]

Fig. $7 \quad$ MMC finite element model and loading conditions

Fig. 8 Number of cycles to failure against creep dwell time for EPP and RO material models for a cycling temperature $\theta_{0}=175^{\circ} \mathrm{C}$ and constant mechanical load $\sigma_{\mathrm{p}}=86.25 \mathrm{MPa}$

Fig. 9 Creep-Fatigue interaction diagram, fatigue and creep damage against dwell time plots for a uniform cycling temperature $\theta_{0}=175^{\circ} \mathrm{C}$, and different constant mechanical loads at (a) $0 \mathrm{MPa}$, (b) 86.25 MPa, (c) $172.5 \mathrm{MPa}$

Fig. 10 Stress contours normalized by the yield stress at loading, creep and unloading for a uniform cycling temperature $\theta_{0}=175^{\circ} \mathrm{C}$ and constant mechanical load $\sigma_{\mathrm{p}}=172.25 \mathrm{MPa}$ at different dwell times

Fig.11 Strain contours at loading, creep and unloading for a uniform cycling temperature $\theta_{0}=$ $175^{\circ} \mathrm{C}$ and constant mechanical load $\sigma_{\mathrm{p}}=172.25 \mathrm{MPa}$ at different dwell times 

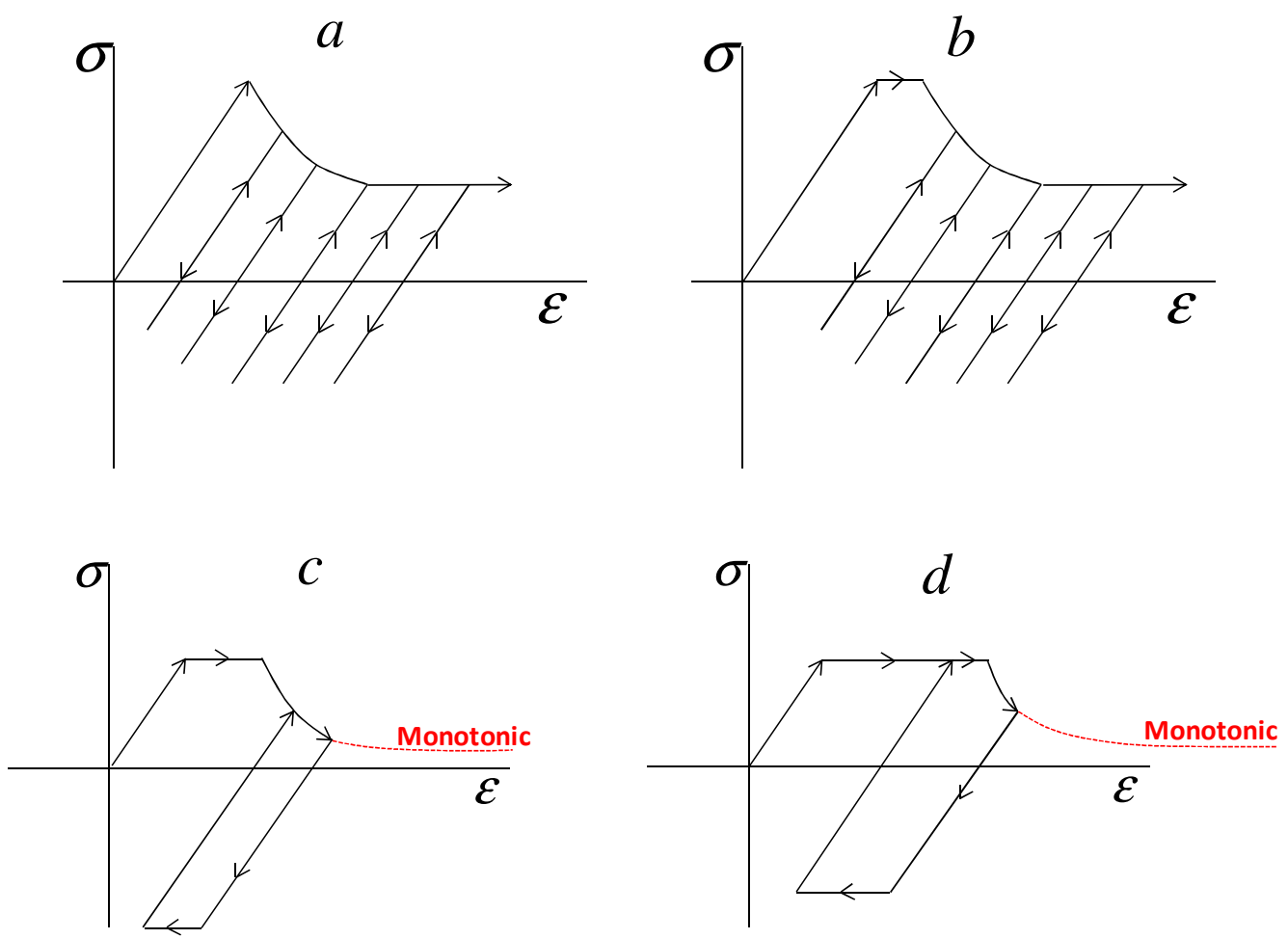

Fig. 1 Different material responses due to cyclic loading with creep dwell period at the tensile peak 


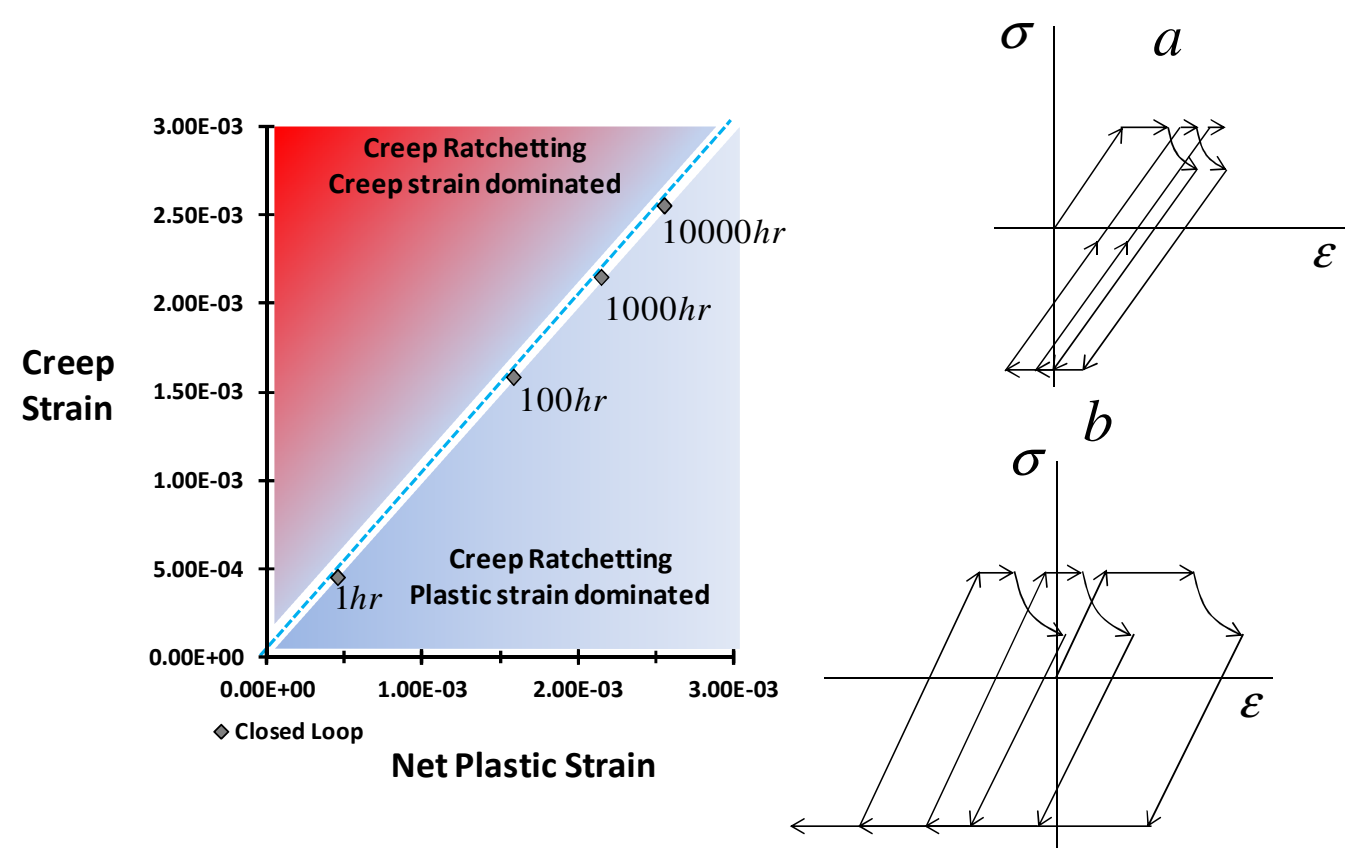

Fig. 2 Creep ratchetting interaction boundary and creep ratchetting response due to creep stain (a) and plastic strain (b) 


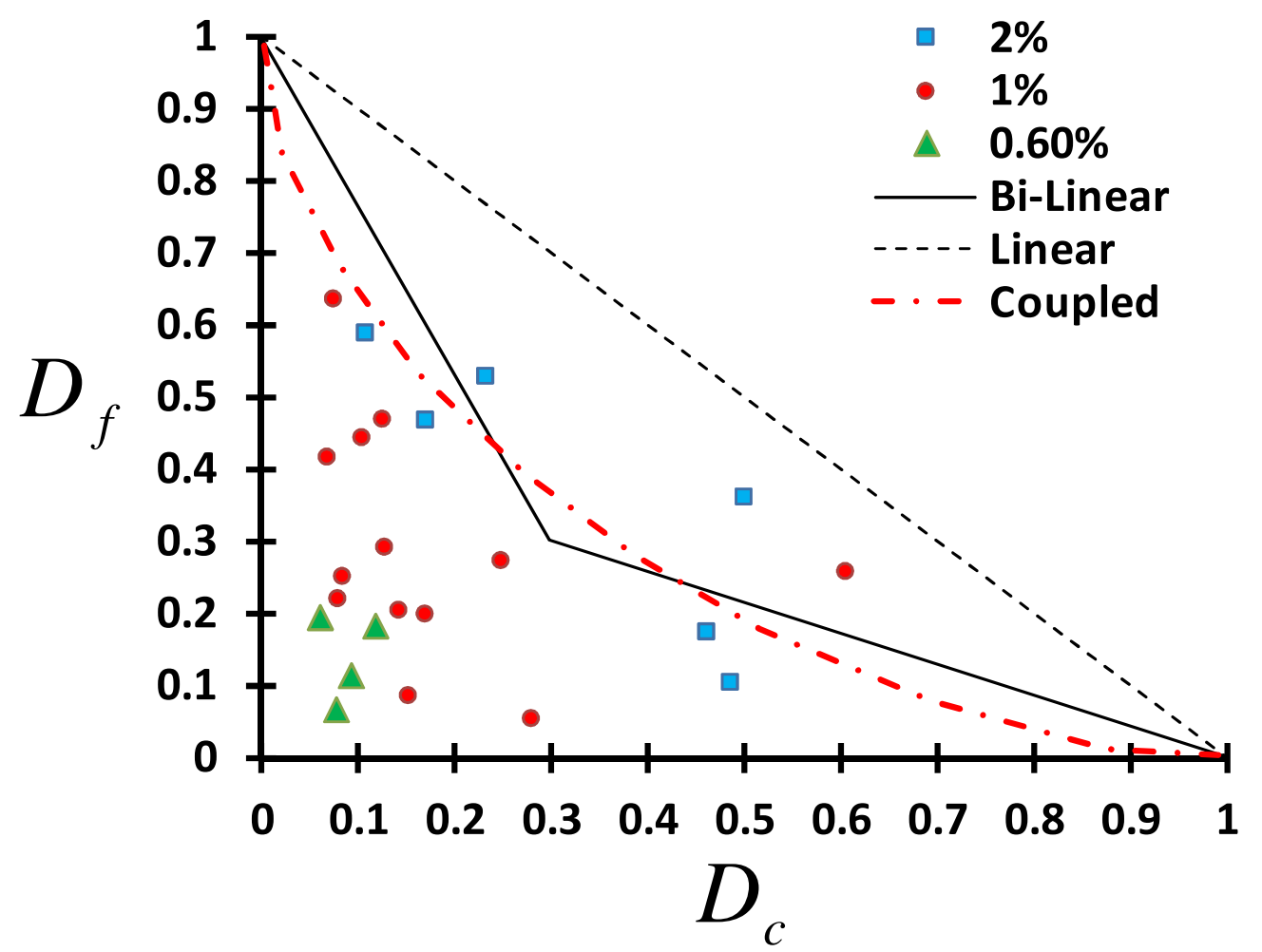

Fig. 3 Type $304 S S\left(595^{\circ} \mathrm{C}\right)$ damage diagram for bi-linear, linear and combined damage rules [28, 29] 


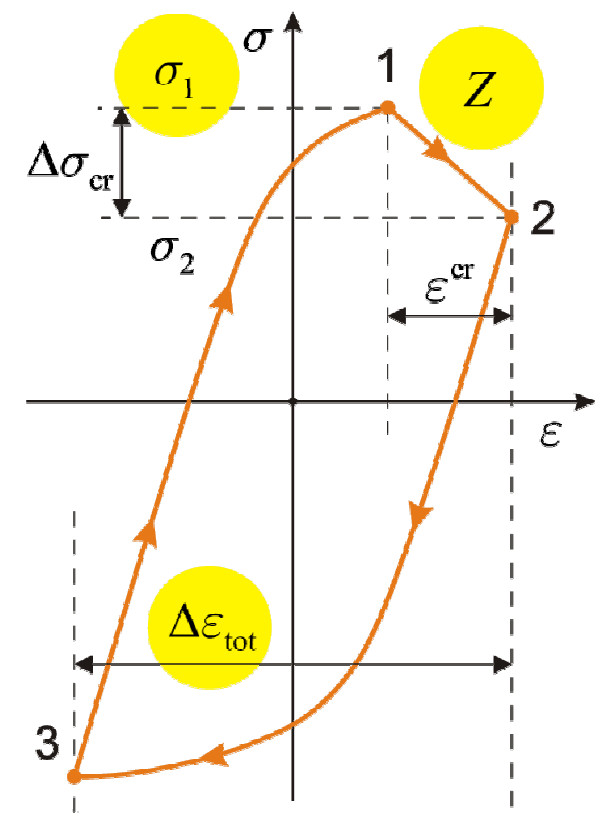

Fig. 4 Saturated Steady State Cycle with creep dwell at tensile peak 

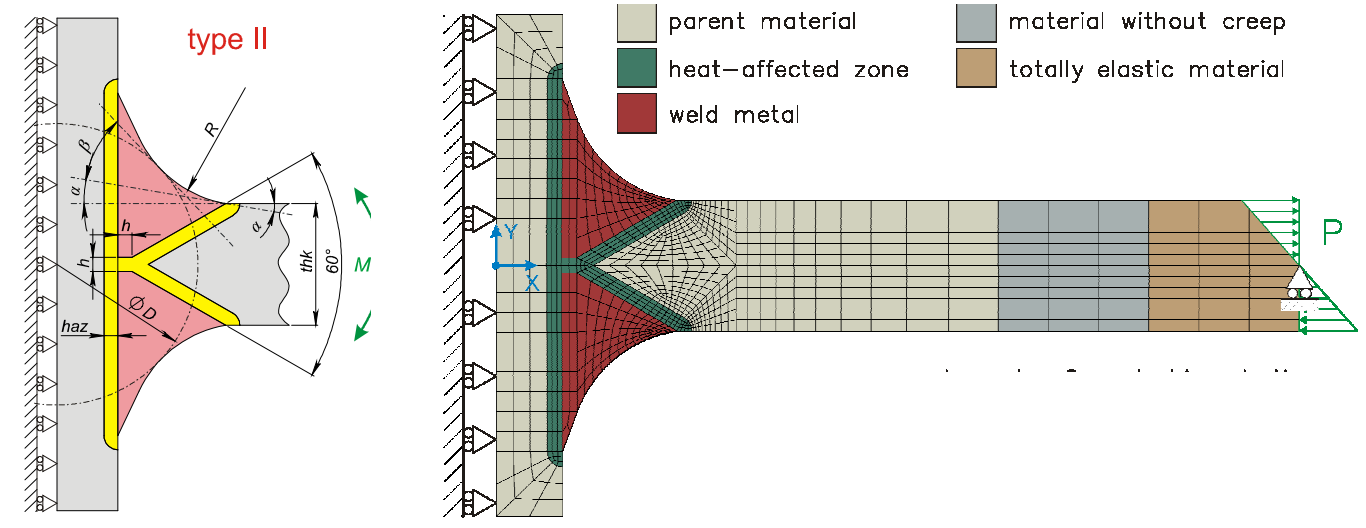

Fig. 5 Geometry and Finite Element Model of type 2 cruciform weldment [12] 

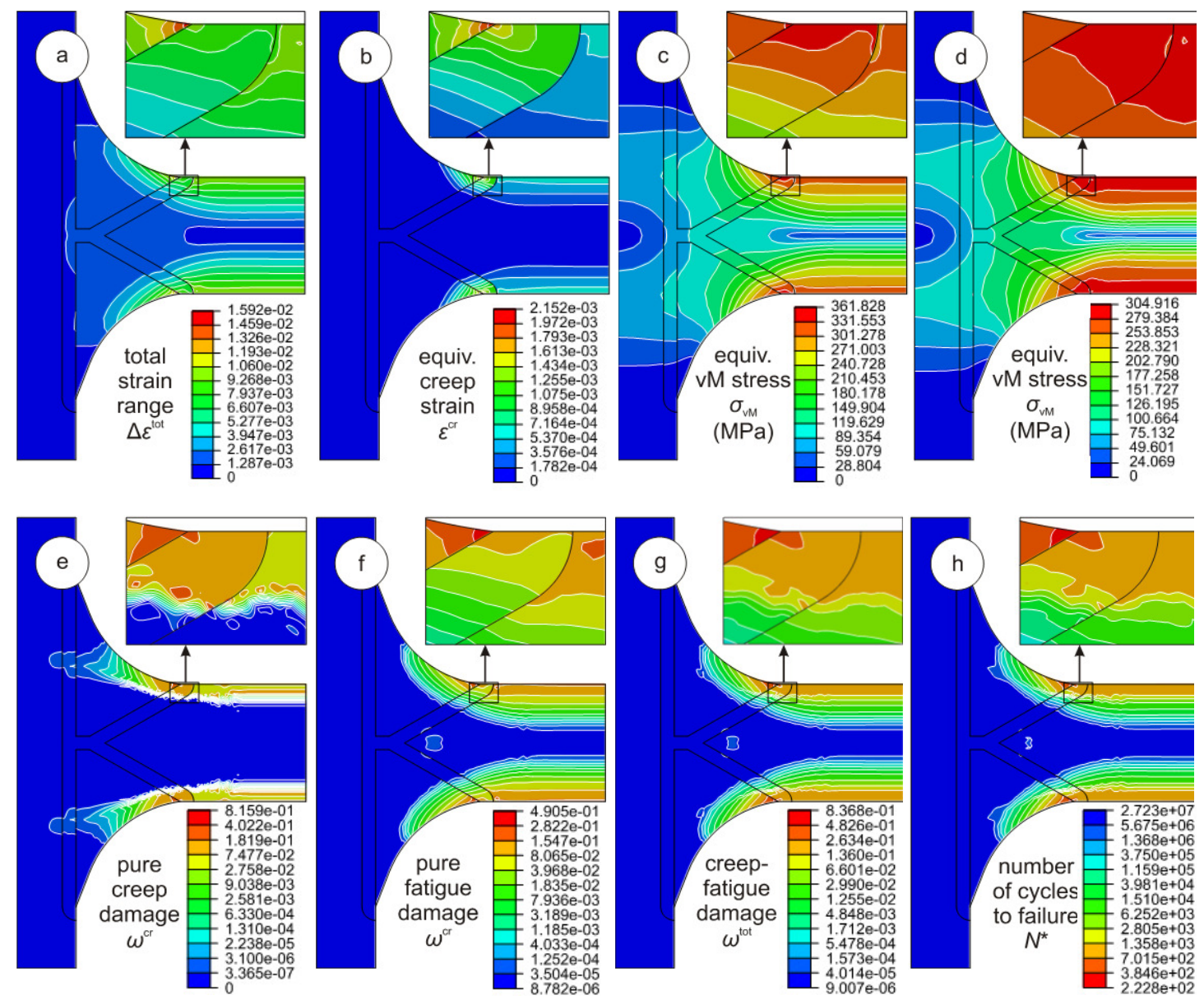

Fig. 6 Contour plots of LMM results for type 2 weldment corresponding to $\Delta \varepsilon_{\text {tot }}=1 \%$ and $\Delta t=5$ hours of dwell period [12] 

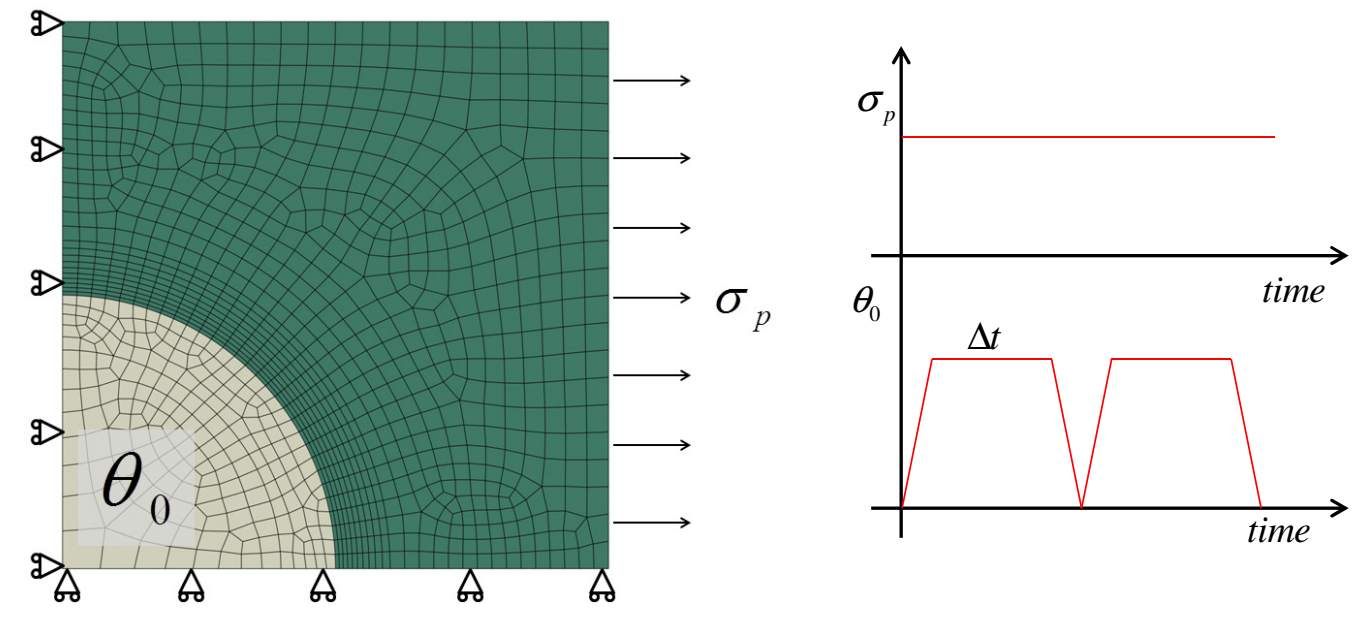

Fig. $7 \mathrm{MMC}$ finite element model and loading condition 


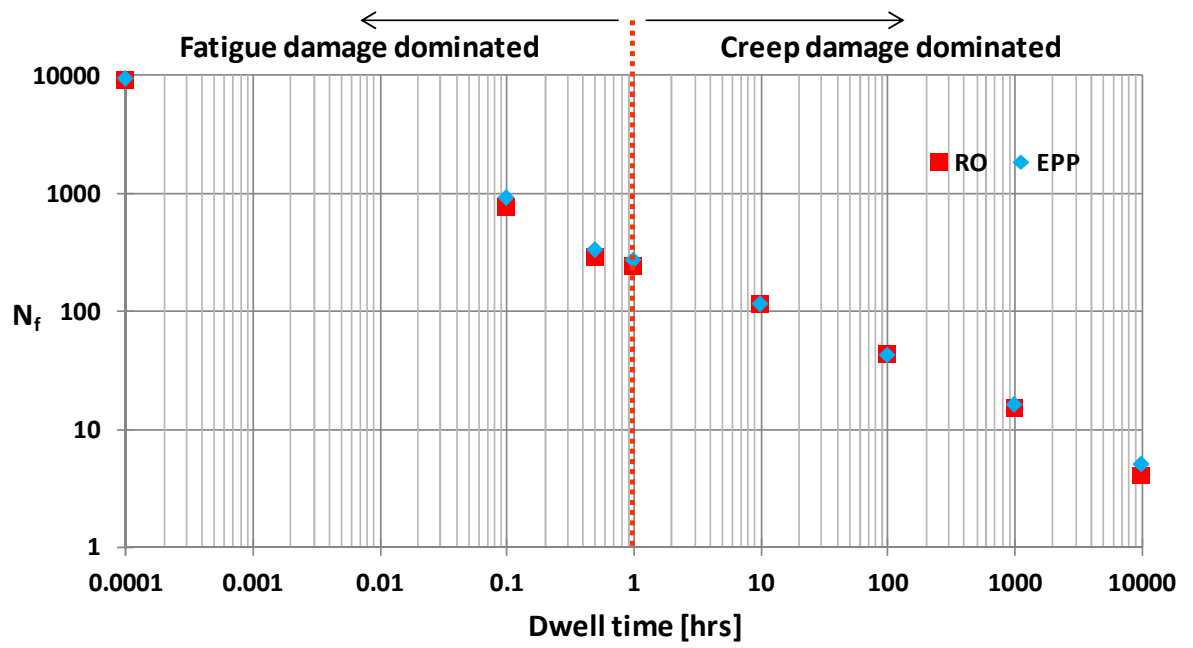

Fig. 8 Number of cycles to failure against creep dwell time for EPP and RO material models for a cycling temperature $\theta_{0}=175^{\circ} \mathrm{C}$ and constant mechanical load $\sigma_{p}=86.25 \mathrm{MPa}$ 

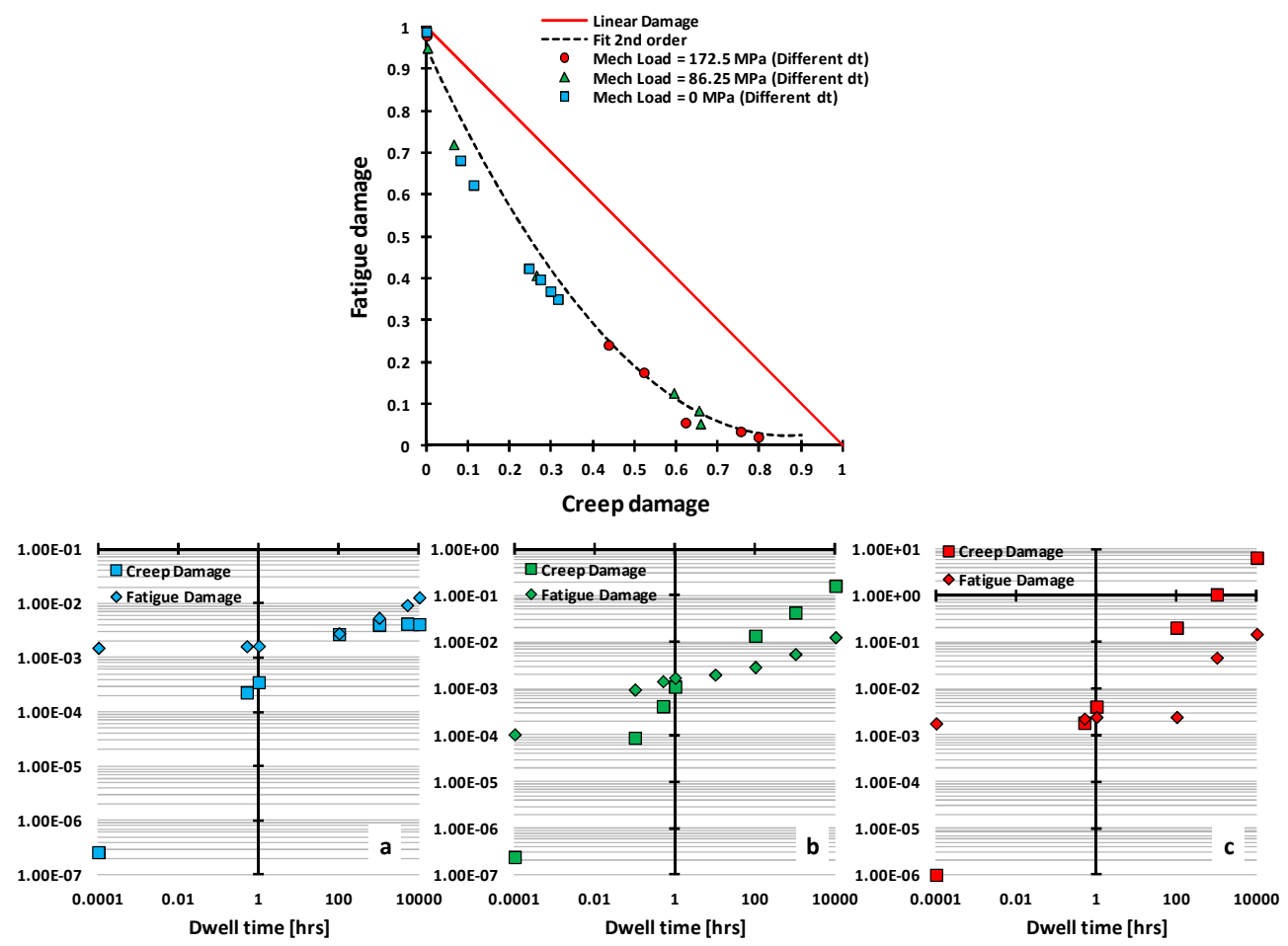

Fig. 9 Creep-Fatigue interaction diagram, fatigue and creep damage against dwell time plots for a uniform cycling temperature $\theta_{0}=175^{\circ} \mathrm{C}$ and different constant mechanical loads at (a) $0 \mathrm{MPa}$, (b) 86.25 $\mathrm{MPa}$, (c) $172.5 \mathrm{MPa}$ 


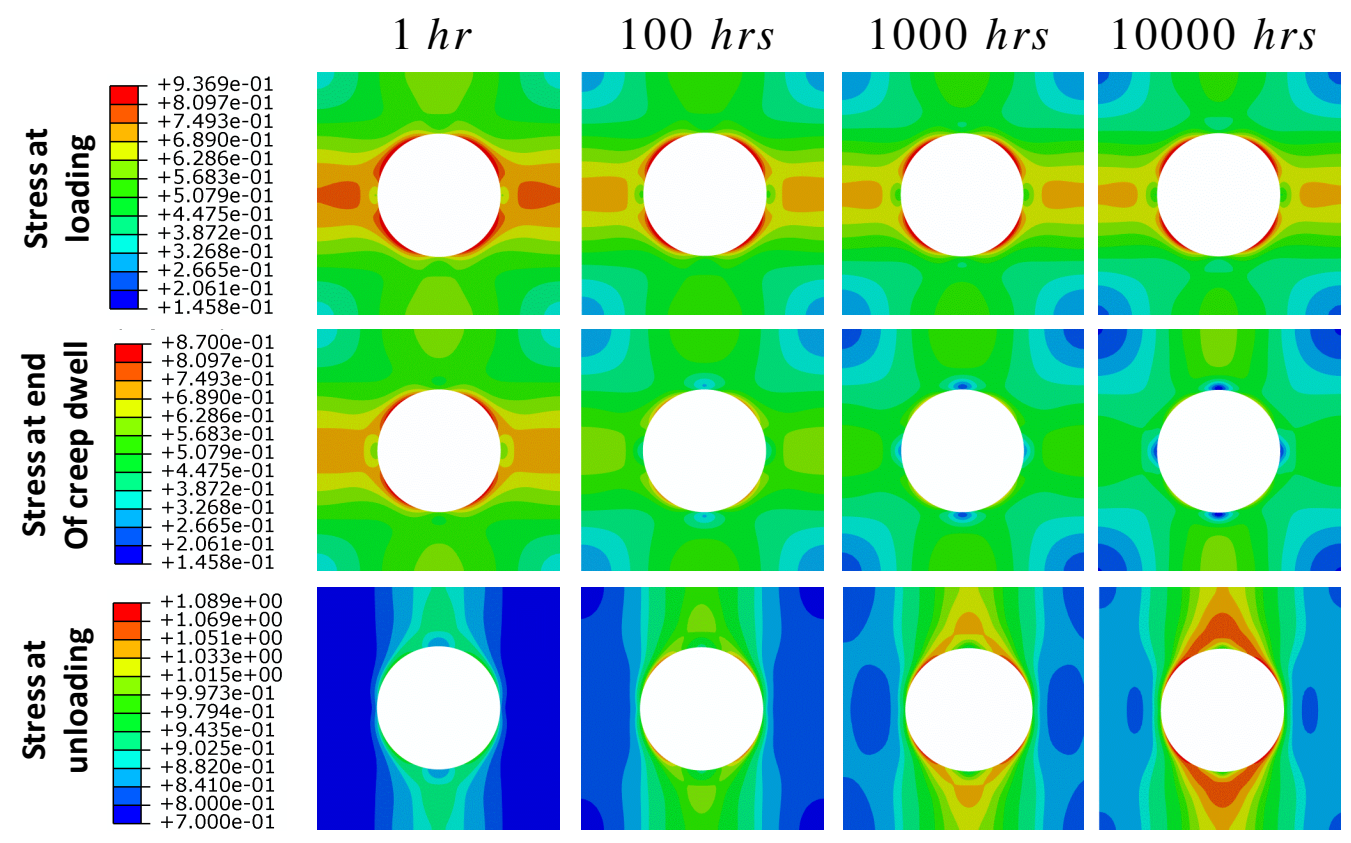

Fig. 10 Stress contours normalized by the yield stress at loading, creep and unloading for a uniform cycling temperature $\theta_{0}=175^{\circ} \mathrm{C}$ and constant mechanical load $\sigma_{\mathrm{p}}=172.25 \mathrm{MPa}$ at different dwell times 


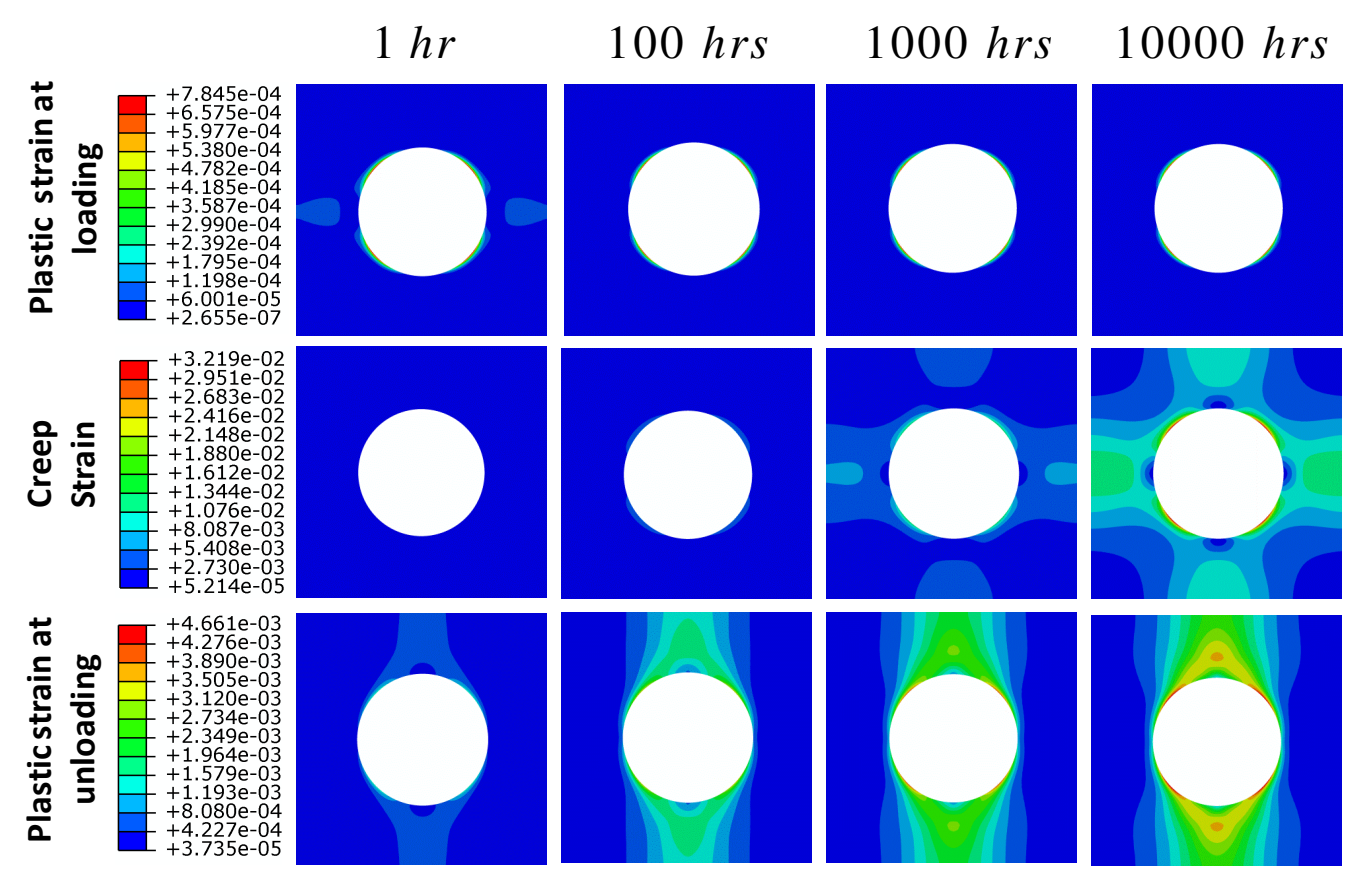

Fig. 11 Strain contours at loading, creep and unloading for a uniform cycling temperature $\theta_{0}=175^{\circ} \mathrm{C}$ and

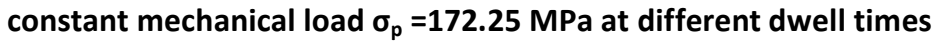

